Lengua y Sociedad en el Mundo Hispánico

Language and Society in the Hispanic World

Editado por / Edited by

Julio Calvo Pérez (Universitat de València)

Luis Fernando Lara (E1 Colegio de México) Matthias Perl (Universität Mainz)

Armin Schwegler (University of California, Irvine)

Klaus Zimmermann (Universität Bremen)
Yolanda Congosto Martín

Elena Méndez García de Paredes (eds.)

\section{Variación linguiística y contacto de lenguas en el mundo hispánico}

In memoriam MANUEl Alvar

Vol. 27 


\title{
EL LENGUAJE PERIODÍSTICO COMO CATALIZADOR DEL CAMBIO LINGÜÍSTICO: LA PÉRDIDA DE LA DEFECTIVIDAD VERBAL EN AGREDIR ${ }^{1}$
}

\author{
ARACELI LÓPEZ SERENA / LOLA PONS RODRÍGUEZ \\ Universidad de Sevilla
}

\section{Introducción}

\subsection{Objetivos del trabajo}

Los denominados verbos defectivos ocupan un lugar singular en la morfología verbal del español, tanto por el tipo especifico de irregularidad que presentan, como por la aparente mayor permisividad que, con respecto a usos tradicionalmente condenados por la norma prescriptiva, manifiestan en la sincronía actual. Por lo que respecta, por ejemplo, al lenguaje periodístico (termómetro gramatical por excelencia del estado actual de la lengua), no sólo los diferentes medios de comunicación, sino incluso los libros de estilo por los que estos se rigen, han mostrado una gradual apertura hacia el fenómeno de variación que ha convertido en regulares a verbos que tradicionalmente se tenían por defectivos en nuestro idioma (agredir, abolir, transgredir...). Nuestra investigación atenderá a este hecho de variación vivo en la actualidad en español: la tenđencia a la regularización de verbos defectivos (a partir del estudio de caso de agredir), con la intención de

1. Este trabajo constituye una parte de una labor de investigación de mayor envergadura, de cuyos resultados, por restricciones de espacio, resulta imposible dar cuenta únicamente en las páginas que ocupa la presente contribución. Una versión ampliada, elaborada por las mismas autoras, y en la que se vuelven a abordar con mayor extensión y profundidad algunos problemas de los aquí tratados (y otros nuevos) aparece en el Boletín de la Real Academia Españo$l a$, con el título "Un episodio de la morfología histórica del español: la pérdida de la defectividad verbal en los medios, las gramáticas y el uso" (cf. Pons Rodríguez/López Serena 2007). Aunque se trata de un trabajo posterior a éste en el tiempo y en su contenido, los avatares editoriales han hecho que, paradójicamente, termine ostentando una fectha anterior. 
observar de forma comparativa el desarrollo de usos lingüísticos innovadores y el eco paralelo que de esas innovaciones se filtra en los textos metalingüísticos².

Dado el fenómeno, constante en todas las lenguas e inherente al propio lengua$\mathrm{je}^{3}$, del cambio lingüístico, y teniendo en cuenta la existencia en el contexto lingǘstico español de frenos normativos al cambio, en este trabajo tratamos de presentar las bases necesarias para poder proseguir, en estudios posteriores, con la crónica detallada de cómo una tendencia de cambio - en este caso la propensión analógica de los verbos - es reflejada en los productos metalingüísticos. Nuestro propósito final es, por tanto, observar cómo se proscribe, prescribe y describe en relación con fenómenos como la compleción de la conjugación de verbos defectivos, observando simultáneamente, a través de pesquisas en corpus y colecciones textuales, las coincidencias o más que posibles divergencias entre el uso y la norma. El proceso de extensión de la proporcionalidad que se observa en la historia de los verbos defectivos ha sido registrado por la historia normativa del español, y nuestro trabajo - del que aquí nos tendremos que contentar con presentar únicamente sus directrices y ceñinos exclusivamente a un ejemplo- busca describir ese proceso en un intento de tasar la distancia entre ambas realidades: la generalización de una novedad lingüística y el levantamiento de posibles etiquetas censoras en torno a esa novedad.

\subsection{La lengua periodística como corpus}

Dentro de nuestro corpus, hemos dispensado especial atención a la lengua periodística y a los productos metalingüísticos que nacen en torno a ese tipo de lengua, como los libros de estilo de periódicos o los diccionarios de dudas. De entre es-

2. Como señalamos en Pons Rodríguez / López Serena (2007: 60, n. 1), de esta forma, al mismo tiempo que abordamos un hecho de variación vivo en la sincronía, creemos que a la larga podremos contribuir, también, a "rellenar [un] 'hueco' [importante] de la morfulogia histórica", cuya situación ha sido considerada recientemente por Rafael Cano, en un trabajo que repasa las contribuciones hechas a "La morfología histórica del español en los últimos cien años" como no tan favorable, de "estudio [...] minoritario y sin visible capacidad de expansión" (Cano 2004: 71-72). Claro que, se impone decirlo, Cano (1986) ya había constituido una importante contribución al "relleno" de ese "hueco" en nuestros conocimientos sobre morfología histórica de los verbos españoles.

3. De hecho, el cambio lingüístico es, junto con la variación y la diversidad lingüísticas, uno de los corolarios de la historicidad, uno de los universales genérico-esenciales postulados por Coseriu para definir el lenguaje. Cf., a este respecto, Oesterreicher (2006). 
tos, concedemos un lugar importante al Diccionario panhispánico de dudas de la Academia, aunque no únicamente como obra de referencia prescriptiva, sino en su calidad de reflejo de lo que los hispanohablantes "han convertido en hábito de corrección, siguiendo los modelos de la escritura o del habla considerados cultos" (DPD "Presentación": XI). Por una parte, es obvio que, como afirma Francisco Rico (1996: 519), "[c]uando la lengua pierde diafanidad, cuando deja de ser un mero vehículo y plantea dudas o despierta curiosidades, la Academia aparece con toda naturalidad en el horizonte mental del hispanohablante", entre ellos, fundamentalmente, los profesionales de los medios de comunicación. Pero además, en su historia reciente, la Academia ha dejado de concebir su cometido en los términos de limpiar, fijar y dar esplendor, y más bien se propone, de acuerdo con los nuevos estatutos redactados por Fernando Lázaro, "velar por que los cambios que experimente la Lengua Española en su continua adaptación a las necesidades de los hablantes no quiebren la esencial unidad que mantiene en todo el ámbito hispánico" (García de la Concha 2005: 27)4.

Además del interés que por sí misma tiene la lengua periodística como variedad, hay otras razones para elegirla, como el hecho de que sea, por su difusión, en la actualidad, la gran propagadora de procesos de cambio lingüístico. Los periodistas son, sin saberlo, portavoces - y muchas veces también creadores- de las novedades lingüísticas que van desarrollándose en una comunidad. Es evidente que, a este respecto, nos enfrentamos a una especie de "retroalimentación": los periodistas se hacen eco de las novedades (se ha dicho a este respecto que son, por lo tanto, una especie de termómetro gramatical y léxico de una sociedad) y, al mismo tiempo, fomentan y desarrollan en esa sociedad estos fenómenos. Además, el hecho de que para muchos hablantes el único contacto con el estándar y con la lengua más formal sea a través de los medios de comunicación les confiere una enorme responsabilidad en la educación lingüística de la comunidad ${ }^{5}$. De hecho, cuando se aborda la cuestión de los tipos de ejemplaridad predominantes en la historia del español (Méndez 1999), se constata que, mientras que al menos hasta el Esbozo la norma preceptiva se fundaba en un ideal de lengua literario, en la actualidad, el ideal de lengua es más bien el de los medios de comunicación. Consciente de esta situación, la Real Academia ha llegado a celebrar congresos dedicados específicamente a la lengua de los medios de comunicación. En 1985 se celebró la Primera Reunión de

4. Sobre la unidad del español, se puede ver también Coseriu (1990).

5. Sobre la responsabilidad idiomática de los profesionales de los medios de comunicación, cf., por ejemplo, Comisión Permanente de la Asociación de Academias de la Lengua Española 1987; Seco 1994; Martínez Albertos 1990, 2003. 
Academias de la Lengua Española sobre el Lenguaje y los Medios de Comunicación, cuyas actas se publicaron en 1987. En el texto de la sesión inaugural de esta reunión, Pedro Laín Entralgo (1987: 14) llamaba la atención sobre el papel de "los medios sociales de la comunicación verbal - la prensa, la radio y la televisión[como] los más eficaces recursos para mantener la unidad nacional y supranacional del idioma, [que] pueden ser, si no se cuida su lenguaje, los agentes más temibles de su deterioro y su fragmentación".

Por su importancia en cuanto catalizadores del cambio lingüístico, los estudios de carácter normativo sobre el lenguaje en el ámbito periodístico han atendido tradicionalmente a los denominados exempla vitanda, esto es, errores y desviaciones gramaticales difundidos en los medios de comunicación. Tales desviaciones se denuncian con la pretensión de evitar que el lenguaje periodístico se constituya en lengua especial o profesional (con marcas diferenciales del oficio) y deje de ser lo que realmente es: un lenguaje general común a los miembros de una comunidad lingüística (Lázaro 1990: 25). Sin embargo, en la actualidad, parece que, sobre todo por lo que respecta al lenguaje televisivo, más que hacia la constitución de un lenguaje de especialidad, el uso lingüístico de los medios audiovisuales tiende hacia una mayor uniformidad en todo el mundo hispano, hasta el punto de que, frente a la fragmentación del latín (temida por Rufino José Cuervo para el español tras la independencia de los países hispanoamericamos), se ha llegado a pronosticar que, gracias a la unidad promovida en la actualidad por los medios de comunicación, "el conocimiento mutuo engendraría una koiné hispánica que, así como la koiné helenística prolongó la unidad del lenguaje en el mundo griego, hiciese perdurar durante siglos y siglos la básica unidad de la lengua española, a la vez una y varia" (Lapesa 1987: 20-21).

Además de en relación con la norma prescriptiva o norma ejemplar, la lengua periodística constituye un excelente campo de observación de la tensión constante que, en el uso lingüístico, se da entre el sistema y la norma consuetudinaria, es decir, la norma en el sentido coseriano del término. La regularización, como tensión entre sistema y norma, y la creación analógica son ejemplificadas por Coseriu, "[p]or lo que concierne a la distinción entre norma y sistema en el campo de la morfología" mediante un fenómeno de habla, los "errores de flexión que hacen los niños, o, en general, las personas que no conocen suficientemente la norma" (Coseriu 1952[1973³]: 75). En nuestro caso, la pérdida de defectividad de ciertos verbos a lo largo de la historia del español y en la actualidad constituyen, más que un mero hecho de habla, la constatación de un cambio lingüístico analógico consistente en la sustitución, primero en la norma consuetudinaria y después en 
la ejemplar o prescriptiva - de ahí que analicemos las obras que codifican el estándar de una comunidad--, de lo asistemático por lo sistemático.

Así las cosas, en este trabajo queremos esbozar muy brevemente cuáles son las principales dificultades que presenta la investigación sobre los verbos defectivos, para posteriormente, de la mano de un ejemplo concreto, comprobar, en qué medida es cierta la atribución, a los medios de comunicación, de la máxima responsabilidad en la catalización de los procesos de cambio lingüístico, que, como es sabido, suele presentarse como un a priori en las reflexiones sobre la responsabilidad lingüística de periodistas, locutores y otros profesionales de los medios de comunicación.

\section{Problemas teóricos y metodológicos en el estudio de la defectividad}

Una primera dificultad que se presenta en la investigación sobre los verbos defectivos del español es la constatable existencia de discrepancias entre los gramáticos sobre cuál sea el catálogo de verbos defectivos de nuestro idioma. Tal situación se deriva de la propia variabilidad a la hora de definir la noción de defectividad. No ha existido apenas, bien es cierto, discusión teórica acerca de qué se engloba bajo tal noción ni tampoco se plasma de manera explícita el disenso de unos autores con otros. Más bien lo que hallamos es un conjunto de informaciones sobre la defectividad dispersas en gramáticas, diccionarios, monografías sobre cuestiones verbales o trabajos sobre norma del español actual.

En cualquier caso, al margen del tratamiento teórico y gramaticográfico de lo defectivo - en que no necesitamos volver a entrar aquí, puesto que ya lo hemos abordado en otro lugar (cfr. Pons Rodríguez / López Serena 2007)-, en general, lo habitual es distinguir entre la defectividad que atañe a la morfología nominal (generalmente referida a los llamados singularia y pluralia tantum) y la que afecta al verbo. En este último terreno, el que nos interesa a nosotras en este trabajo, es notablemente amplio el conjunto de fenómenos que históricamente han cabido bajo la idea de defectividad. Así, a este respecto, las gramáticas han contemplado motivos muy diversos de defectividad y han distinguido, en consecuencia: verbos defectivos por carencia de ciertas personas, por carencia de determinados tiempos, por la dificultad de incorporar a su paradigma formas presumiblemente irregulares, o por motivos semánticos, entre otros.

Una segunda dificultad, como señaló Elvira (1989), es de índole sintáctica, en la medida en que en ocasiones se postulan infinitivos de supuestos verbos de- 
fectivos que sólo se atestiguan en participios difícilmente analizables como otra cosa que adjetivos verbales. Así, dentro del grupo de verbos que pretendidamente son defectivos según publicaciones varias de gramática sincrónica (e incluso de acuerdo con antiguas gramáticas del español), se incluyen formas en infinitivo que no parecen haberse documentado nunca en el español; tal cuestión fue puesta de relieve por Malkiel (1941), quien llamó la atención sobre el espejismo lexicográfico de la documentación en diccionarios del español de infinitivos derivados retrospectivamente desde adjetivos acabados en -ado o -ido, adjetivos que, pese a su coincidencia formal con participios, no dejan huella de uso como verbos en la historia del español. Es decir, que existan amodorrido, florido o empedernido no implica que se hayan dado unos correspondientes infinitivos: amodorrir, florir, empedernir, formas que ocasionalmente son dadas por existentes y calificadas como verbos defectivos.

Con todo, aparte de los casos en que las gramáticas operan al margen del uso e inventan infinitivos y formas conjugadas de supuestos verbos defectivos, y volviendo a las dificultades en la definición de defectividad a las que hacíamos alusión antes, es interesante constatar que de la disparidad de teorías acerca de qué es la defectividad se deriva otro hecho: la discrepancia que se constata en las nóminas que los diferentes gramáticos dan acerca de qué verbos son defectivos en español. En ocasiones, por lo que respecta a la falta de coincidencia en la nómina de verbos defectivos propuestos por los distintos gramáticos, las diferencias entre autores de épocas distintas pueden llegar a interpretarse como indicios de cambios. Así, por ejemplo, la desaparición de agredir del elenco de verbos defectivos enumerados por la $G D L E^{6}$ (que contempla los siguientes: abolir, acaecer, acontecer, acostumbrar, adir, atardecer, balbucir, compungir, desabrir, descolorir, desvair, embair, embebecer, empedernir, fallir, licuefacer, preterir, rarefacer, sarpullir, transgredir, usucapir) es síntoma claro del proceso de regularización que ha experimentado hasta llegar a ser utilizado, en la actualidad, en formas que no poseen la letra $i$ en su conjugación. Sin embargo, en otras ocasiones, no se puede hablar de posibles cambios en marcha como causas del desacuerdo ${ }^{7}$. De hecho, en la historiografía lingüística española lo más habitual no ha sido eliminar de la lista de verbos defectivos ofrecidos por las gramáticas algunos antiguamente defectivos ya regularizados, sino más bien ir añadiendo nuevos casos a

6. Cf. Alcoba (1999), en: Bosque / Demonte, dirs. (1999).

7. Cf. las discrepancias que rastrea Elvira (1989) entre las gramáticas de Salvá, Bello y académicas de 1771 y 1917 , entre otras. 
los recogidos por la tradición gramaticográfica anterior, tal como exponemos en Pons Rodríguez / López Serena (2007).

\section{La regularización del paradigma de agredir}

El caso particular del verbo agredir puede funcionar como ejemplo paradigmático de ese proceso de acomodación a los parámetros morfológicos de uniformidad y transparencia seguidos por algunos verbos defectivos en español actual: progresivamente este verbo adquiere los exponentes formales del resto de verbos regulares.

Agredir es, pues, un verbo representativo (quizá el que más) de la cuestión que estamos examinando aquí, ya que presenta una defectividad explicable diacrónicamente pero sin que se observe "fundamento sincrónico actual para establecer una relación entre la manifestación o no de la vocal temática /i/ y el uso o no de la forma flexiva correspondiente" (Alcoba 1999: 4968). Por esa falta de motivación sincrónica para la defectividad, puede explicarse el hecho de que este verbo haya pasado de estar normativamente excluido de toda posibilidad de conjugación carente de $/ \mathrm{i} /$ temática a ser considerado regular, no defectivo y conjugable en todos los tiempos, con $/ \mathrm{i} / \mathrm{o}$ con $/ \mathrm{e} /$.

Su defectividad está, en efecto, históricamente motivada; agredir, del lat. AGGREDIOR-GRESSUS SUM 'dirigirse hacia', 'atacar' es según Corominas-Pacual de documentación tardía en el idioma (del siglo xIX, no está aún en el DRAE de $1884^{8}$ ), aunque sí se conocieran desde el Siglo de Oro derivados de AGGREDI como agresión, agresor, digresión, etc. Deponente de la tercera conjugación en latín, este verbo se introduce en castellano con el sufijo verbal en -ir y no en -er debido a la atracción que la tercera conjugación castellana ejerce en la adaptación morfológica de verbos cultos (Elvira 1993 y 1998). La incorporación de esta voz en el español decimonónico suscitó dos reacciones normativas, relativas tanto a su forma defectiva como a su significación ${ }^{8}$. Así, su significado bascula entre el de

8. De hecho, la primera documentación que ofrece CORDE para agredir data del siglo XIX y se ubica en el español americano (1881, Juan Vicuña Mackenna, La campaña de Lima); los ejemplos de español peninsular tardan una década más en manifestarse. Aparece en la lexicografía académica desde 1914; a partir de 1927 se incluye información sobre su carácter defectivo, con el aviso: "Se usa en las mismas formas que aguerrir"; dicha información desaparece $(1939,1947,1956,1970)$ y aparece $(1950,1984,1988$ y 1992) en ediciones posteriores (datos del NTLLE). 
'atacar' y el más ortodoxo etimológicamente de 'aproximarse', y este fue el pretendido por autores puristas como el padre Juan Mir y Noguera en su Prontuario de hispanismo y barbarismo (1908):

Si hemos de estar al sentido del latino "aggredi", el verbo agredir significará acercarse a alguno. Agredir un asunto será emprenderle; agredir un discurso será comenzarle; agredir a una dificultad será satisfacer a ella. Con estas acepciones propias del latín "aggredi", se tendrá que conformar el nuevo agredir, si ha de ir consiguiente (Mir 1908, s.v. agredir).

Le otorgan carácter defectivo también tempranamente autores como Cuervo $(1955)^{9}$ : "Para que haga juego con agresión, agresor, usan algunos el verbo agredir, como anteriormente se hizo con transgredir; pero estos verbos se resisten a ser conjugados en todas las inflexiones".

Para un verbo de la tercera con vocal radical e como agredir, eran posibles dos conjugaciones: una conjugación apofónica -que por ejemplo sigue medir: $m i$ do-medimos... - o una conjugación con diptongo alternante en los presentes de indicativo y subjuntivo - la que tiene mentir: miento, mienta - Ambas opciones de conjugación tienen en común una serie de formas: la primera y segunda personas del plural del presente de indicativo (agredimos, agredis); el paradigma completo del imperfecto de indicativo, indefinido, futuro de indicativo y condicional (agredia, agredió, agredirá, agrediría ${ }^{10}$ ) y todo el paradigma de tiempos compuestos (con participio agredido). Tales son las formas que, históricamente, han sido "toleradas" para la conjugación del verbo agredir, formas todas ellas con $i$ en la desinencia y que coinciden con las formas débiles del verbo. El resto de las formas (las formas fuertes: 1.a 2 . $^{a}, 3$. $^{a}$ persona del singular y 3 . $^{\mathrm{a}}$ del plural del presente de indicativo y del subjuntivo) no eran conjugables al carecer de desinencia en -i. Así, se evitó históricamente una fluctuación entre una conjugación

9. También se debatió en torno a la pertinencia de la introducción de esta nueva voz en español. Así, en su reseña al Diccionario de galicismos de Rafael Baralt (1855), Andrés Bello aprobaba el uso de ese nuevo verbo agredir: "Tenemos agresión y agresor, agresora; ¿por qué no hemos de tener, como los franceses, agresivo, agresiva y agresivamente? También poseen ellos el verbo agresser, que entre nosotros podría ser muy bien agredir. Todo ello viene de la fuente común, de la madre latina, que decía aggressio, -onis; aggressor, -oris; aggredior, -edi".

10. Con respecto al indefinido, el modelo de medir daría en agredir unas formas *agridió y *agridieron que no parecen haber sido competencia para agredió y agredieron, dada la conocida acción metafónica vacilante de la yod de los pretéritos sobre la vocal radical de los verbos en $-i r$. 
apofónica — del tipo *agrido, *agrides, *agride, *agriden o subjuntivo *agridao con diptongo alternante — esto es: *agriedo, *agrieda-. De alguna de esas formas encontramos documentación en la historia del español; Fernández Ramírez (1986: 200, n. 10) halla formas como agriede o agriden ${ }^{11}$ que, por su rareza, es lógico que no dejen muestras en nuestras búsquedas en bases de datos como coRDE, CREA, Iconoce y en el Corpus del español de Mark Davies.

Este problema de conjugación es superado cuando, como afirma Javier Elvira (1998: 176): "la relación entre el timbre del radical y la clase flexiva deja de ser percibida por los hablantes y se convierte en algo anormal desde el punto de vista del sistema". Ello explica el movimiento paulatino de generalización de una conjugación sin alomorfia para este verbo de la tercera: agredo, agredes, agrede. La conjugación aparentemente más "regular" es la más rara para los verbos de la tercera. Hay que recordar que, junto con agredir, los únicos tres casos de verbos de la tercera conjugación con vocal radical -e- que no se acomodan ni al modelo diptongado ni al metafónico son convergir (que, por otro lado, conoce la variante converger), divergir y sumergir, los cuales, llegados al español como formas cultas después del español áureo, no alteran su raiz en ningún lugar del paradigma. Son verbos infrecuentes que tienen el mismo modelo de conjugación que adopta agredir en el siglo $\mathrm{xx}$, superada la extrañeza de las primeras documentaciones y la reglamentación normativa contraria. Tal cambio lingüístico hacia la regularidad de agredir es muy tardío. En CORDE sólo hay un caso de agrede hasta 1950, y muy pocos más hasta los años setenta, fecha en que se disparan las documentaciones de conjugaciones con -e de este verbo; en CREA las documentaciones superan el centenar desde 1975 hasta 2007:

(1) En esto, surges tú de la enramada, como aparición trágica, lívido, descompuesto, con los ojos centelleantes, las manos crispadas, y te increpa, le vituperas, le agredes... Suena un $; a y ![. .$.$] , dos gritos, y este te da a ti cuatro bofetadas... (1916,$ Carlos Arniches, La señorita de Trevelez) // —Usted debe saber -insistió- la penalidad en que incurre el que agrede a un agente... (1956, Lorenzo Villalonga, Bearn o la sala de muñecas) // El pequeño, en suma, no es casto, coge dinero, falta a clase, miente, insulta, agrede, guarda rencor, es cruel... (1968, J. L. Martín Vigil, Los curas comunistas).

(2) En aquel trecho en que se unen, o se besan, o se agreden el océano y el lago, que-

11. "El ciclista transgride la parada obligatoria de los vehículos" (Ramón Gómez de la Serna, Flor de greguerias, 134), "Los personajes se agriden de palabra y de obra" (A. Marna, $A B C, 14$ de agosto de 1947: 15); "agriede el sentido de la hospitalidad" (M. Soler, $A B C, 5$ de mayo de 1955). 
daban entre dos aguas algunos peces marinos (1973, Pablo Neruda, Confieso que he vivido) // Afirmó que la prioridad de los compromisos militares interárabes de Egipto sobre el tratado de paz se aplicaría solo si Israel agrede un país árabe (Clarín, Argentina, 22/03/1979) // De modo, entonces, que el señor Martínez me agrede por una sola razón (Revista Hoy, Chile, 24-30/12/1984) // Si en lugar de una amonestación a un individuo que agrede a otro cotidianamente se aplican las leyes con rigor, se protege mejor a la sociedad (El País, 01/12/1986) // Un preso etarra agrede a puñetazos a un funcionario de la cárcel de Málaga $(A B C, 04 / 08 / 1989)$ //En Proceso 1045, en una nota del reportero Felipe Cobián sobre la problemática del enjarre del Instituto Cabañas de Guadalajara, el arquitecto Alfredo Varela me agrede diciendo... (Agencia de Información Proceso, México, 15/12/1996) // [...] eso cuenta mucho a la hora de medir el tamaño de la reacción y su consecuencia, porque no es lo mismo cuando a uno lo agrede un enemigo que se precia de que de su lado tiene amplia libertad de acción (El Universal, Venezuela, 10/02/1997) // Mi hermano Gabriel fue atacado el 11 de marzo, cuando conducia su vehículo y fue herido en el corazón, en el cuello y en la frente, por lo que necesitamos saber si se trata de los mismos agresores, ya que por segunda vez se agrede a un miembro de la familia, dijo (Siglo Veintiuno, Guatemala, 02/04/1997) // Para ella, al principio las relaciones interpersonales no fueron fáciles, ya que, al parecer, la personalidad más abierta del dominicano agrede al chileno (Rumbo, República Dominicana, 28/07/1997).

Como se observa, gran parte de la documentación se concentra en prensa hispanohablante $^{12}$. Algunas de las muestras son ejemplos de artículos periodísticos de reflexión sobre el lenguaje, en los que se defiende la consideración del verbo agredir como defectivo:

(3) A propósito de uno de los "trucos" de la semana pasada, publicado en esta página, el lector Luis Velandia H., de Pacho, Cundinamarca, pregunta qué es un verbo defectivo.

Respuesta: Verbo defectivo es el que no tiene todas las desinencias o terminaciones de un verbo regular. Por ejemplo, amar es un verbo regular y tiene siete formas en su presente de indicativo: yo amo, tú amas, él ama, nosotros amamos, vo sotros amáis y ellos aman, según las tablas académicas, más nuestro vos amás, tan usual desde Nicaragua hasta las islas Malvinas.

En cambio, agredir es un verbo que en ese tiempo y modo solo se conjuga en las

12. Con todo, como se ve en los datos de (9), los primeros ejemplos del corde se hallan en novelas, y el primero del CREA se da en un libro de psicología: "El niño se hace agresivo y hostil, y a las madres les sorprende el contraste violento existente entre una y otra actitud. Si hasta ese momento el niño estaba dispuesto a cuidar de sus hermanos y se mostraba sumiso con la madre, ahora agrede a sus hermanos y se rebela contra la madre" (Santiago Ramírez, Infancia es destino. México: Siglo XXI, 1975). 
formas que tienen "i" en la última sílaba: nosotros agredimos, vosotros agredís. Por eso se llama defectivo, porque no son válidas las otras formas (agredo, agre des, agrede, agreden - y con nuestro muy latinoamericano "vos", agredés). De ahí que, como lo señalábamos la semana pasada, no es correcto el título del co mercial de televisión que habla de las pocas especies que "agreden" a sus crías ( $E l$ Tiempo, Colombia, 11/11/1996, "Cartas al defensor del lenguaje").

La pérdida de defectividad de agredir ha sido, por tanto, un fenómeno bastante reciente, lo que explica que hayamos podido asistir "en tiempo real" al paso de una normativización negativa de formas como agrede a su desmarcación y aprobación ante la generalidad de su uso. De este cambio en la normativa del verbo agredir informan diversos textos de reflexión metalingüística. Así, han dado por bueno este empleo las Academias de la lengua, tanto en el DPD (s.v. agredir) -donde se afirma: "Aunque tradicionalmente se ha considerado verbo defectivo, en el español actual ha extendido su empleo a todos los tiempos y personas de la conjugación"-, que, como se sabe, carece de valor normativo, como en el $D R A E$ (22. ${ }^{a}$ ed.) — que sí posee valor prescriptivo-, donde tras una marca de información gramatical, se avisa: "Utilizado antes como defect., el uso ha extendido su empleo a todas las formas de la conjugación". Con todo, algunos libros de estilo, que parecen seguir teniendo como referencia la 21. a edición del $D R A E$, se resisten aún a incorporar la regularización de este verbo. Así, el Libro de redacción de La Vanguardia, de 2004, sigue censurando su uso en las formas tradicionalmente consideradas defectivas:

(4) agredir. Verbo defectivo. Incorrecto: Un ex recluso agrede a su mujer. Correcto: Un ex recluso ataca / golpea / apalea a su mujer.

Claro que los propios redactores de La Vanguardia desobedecen su libro de estilo y no es difícil encontrar en este periódico catalán ejemplos como los siguientes:

(5) El entrenador de Portugal agrede a un jugador serbio (La Vanguardia, 13/09/07 [IConoce]) // Degüella al abogado, se ensaña a golpes con la esposa y agrede bru talmente a las hijas, todo para robar en la vivienda familiar (Ángel Alcaraz, $L a$ Vanguardia, 01/06/06 [IConoce]).

Lo más curioso es que los redactores del libro de estilo de La Vanguardia se hacen eco de que "[d]esde su edición XXI, el DRAE considera que los verbos agredir y transgredir pueden conjugarse en todas sus formas y personas, pero [aun así] este libro mantiene su aspecto defectivo" (La Vanguardia 2004: 144). En la misma línea que este periódico catalán, el Libro de estilo de El País considera que agredir es aún 
un "verbo defectivo que sólo se conjuga en los tiempos y personas que tienen la vocal $i$ en sus desinencias" e incluso añade que "[1] a utilización de 'agrede' es de mal gusto lingüístico" (El País 1996: 200) ${ }^{13}$. Y lo mismo ocurre con el Libro de estilo de $\mathrm{El}$ Mundo (1996: 172). También continúa contemplándolo como defectivo el Libro de estilo de $\mathrm{ABC}$, en su edición más reciente, la 2. ${ }^{\mathrm{a}}$ de 2001 . Este manual dedica un apartado a los verbos defectivos, en cuyo mismo título ya aparece precisamente nuestro verbo: "Verbos defectivos: agredir, diluviar, suceder" ( $A B C 2001^{2}$ : 116). Para $A B C$ "destacan particularmente tres grupos" de verbos defectivos:

-Agredir, transgredir, abolir, preterir, aterir, escarnir... ${ }^{14}$ : deben emplearse solo en las formas cuya desinencia empieza por $i[\ldots]$.

-Verbos de fenómeno atmosférico (amanecer, diluviar, helar, hacer frio, hacer viento/calor/buen día...): conjugados, deben usarse solo en tercera persona del singular.

-Verbos de "suceso" (ocurrir, acaecer, suceder, acontecer): conjugados deben usarse solo en tercera persona (singular o plural) ( $A B C 2001^{2}$ : 116-117).

Con todo, Vigara Tauste, que es la responsable de la redacción del Libro de estilo de $\mathrm{ABC}$, ha de reconocer, en cuanto al primer grupo, al que pertenece agredir que "[s]e trata de una norma difícil" de seguir en el caso de agredir y transgredir, verbos que se utilizan continuamente tanto en la lengua hablada como en la escrita en todas sus formas (agrede, agredia, agredió... [sic])"”.

Obviamente, el uso periodístico de los medios cuyos libros de estilo estamos analizando nos constata, nuevamente, la distancia entre censores y redactores, y no sólo con nuevas formas regulares para tercera persona (6) sino también para primeras y segundas personas (7):

(6) $\mathrm{Y}$ en su decisión ha pesado tanto el hecho de mantener la estabilidad interna con dos pilotos que se conocen, se soportan y no se agreden como el hecho de no incorporar a otros que han criticado abiertamente al equipo (El Pais, 17/10/2007)//

13. $\mathrm{X}$ esto no solo en su undécima edición, que es la que manejamos en papel, sino también en la edición electrónica del Libro de estilo, que se puede consultar en Internet (concretamente para agredir, cf. <http://estudiantes.elpais.es/libroestilo/dic_ag.asp>.

14. Obsérvese que los puntos suspensivos constituyen un síntoma de la falta de acuerdo en cuanto al catálogo de verbos defectivos existentes en español a la que hemos hecho referencia anteriormente.

15. Norma prescriptiva "difícil de seguir" por cuanto que — añadiríamos nosotras - está ya demasiado distanciada de la norma consuetudinaria, que es, en definitiva, la que da sustento a la prescriptiva, en ciernes de desaparición, en la medida en que está obligada a acomodarse a la norma consuetudinaria (la norma en el sentido coseriano del término) que se establece por el uso. 
La recientemente aprobada Ley de Infancia y Adolescencia establece también la sanción social para este delito, los rostros de los violadores ya salen en televisión, el aumento de las penas y la eliminación de los beneficios penitenciarios para los que agredan sexualmente a los niños (El País, 28/09/2007)// Múgica denunció el incumplimiento por parte de las televisiones respecto a no incluir contenidos que agredan la sensibilidad de los menores en horarios infantiles, según el acuerdo existente entre éstas y el Gobierno (El Mundo, 27/06/2006).

(7) Estando en el suelo me agarraron por el pelo y lo único que hice fue tratar de quitarme la mano del contrario, pero no agredo a nadie (La Tribuna de Ciudad Real, 20/09/2007) // Si agredes a una mascota hay dueños que se ven agredidos en los más íntimo, mucho más que si atacases a sus cuñados (Málaga hoy, 07/07/2007) // Dijo que les ha sorprendido "que entre venezolanos tenga que mediar una barra de policía para que no nos agredamos" (El Universal, Venezuela, 16/06/2007).

Por fin, el Libro de estilo de El Periódico de Cataluña es el primero de este tipo (entre los que hemos podido consultar) que se hace eco, no ya solo del uso de agredir en formas que no tienen $i$, sino de que "la RAE ha admitido que este verbo ya no es defectivo y se pueden usar todas las formas de la conjugación". Lástima que como ejemplos de esta nueva conjugación regular proponga, además de "agrede", la forma "agrederán" (sic) (El Periódico de Cataluña 2002: 23).

\section{Conclusión}

En conclusión, por lo que concierne al menos al caso de agredir, no podemos sino constatar la consideración de los medios de comunicación como catalizadores de los procesos de cambio lingüístico. El rastreo de la extensión de las formas regularizadas del verbo agredir, que ha ido perdiendo, a lo largo de su historia, su carácter defectivo confirma empíricamente la verdad de esta aserción. Se verifica, asimismo, que los libros de estilo de los medios de comunicación son bastan te más conservadores que la propia Real Academia, algo que, por otra parte, no es óbice para que sus redactores desoigan las normas ajenas al uso que les dictan los preceptistas de sus respectivos medios.

Ahora bien, lo que en obras sobre el español actual de carácter normativo, entre ellas los libros de estilo de la prensa escrita europea, se presenta sincrónicamente como una mera cuestión de corrección, desde una perspectiva histórica cobra otro perfil distinto, ya que en la observación de por qué estos verbos son defectivos nos tropezamos con un problema de alcance morfológico mayor: el de la adaptación morfológica de cultismos. La pérdida de defectividad está provocada por la nece- 
sidad sincrónica de expresividad, el peso de la analogía y la regularidad (en cuanto a "peso del modelo imitable") en la conjugación verbal, fuerzas comunicativas que no se encuentran frenadas, en el verbo que hemos examinado, por los límites morfológicos sobrevenidos de la necesidad de adoptar el esquema morfofonético de la lengua madre a una lengua hija que ha generalizado esquemas flexivos distintos.

En cualquier caso, queda patente la necesidad de prestar más atención a este capítulo de la morfología, que tan interesantes constataciones históricas y reflexiones teóricas fomenta.

\section{Referencias bibliográficas}

\section{Primaria. Corpus metalingüistico analizado}

$A B C\left(2001^{2}\right)$ : Libro de estilo. Barcelona: Ariel.

AlcobA, Santiago (1999): "La flexión verbal", en: Bosque, Ignacio/Demonte, Violeta (dirs.): Gramática descriptiva de la lengua española. Madrid: Espasa-Calpe, III, 4915-4991.

BELlo, Andrés (1847 [18594]): Gramática de la lengua castellana destinada al uso de los americanos. Caracas: V. Espinal. Recogida en Gómez Asencio, José Jesús (ed.) (2001).

Bosque, Ignacio/Demonte, Violeta (dirs.) (1999): Gramática descriptiva de la lengua española. Madrid: Espasa-Calpe, 3 vols.

CAMPS, Magí (coord.) (2004): La Vanguardia. Libro de redacción. Barcelona: Ariel.

CARDONA, Giorgio Raimondo (1991): Diccionario de Lingüística. Edición española a cargo de M. ${ }^{\text {a }}$ Teresa Cabelio. Barcelona: Ariel.

Corominas, Joan/Pascual, José Antonio (1980): Diccionario crítico etimológico castellano e hispánico. Madrid: Gredos.

Cuervo, Rufino José (1955): Apuntaciones críticas sobre el lenguaje bogotano con frecuente referencia al de los paises Hispano-Americanos. Bogotá: Instituto Caro y Cuervo/Tall. Ed. de la Librería Voluntad ( $9 .^{a}$ ed. corregida).

El Mundo (1996): Libro de estilo. Madrid: Ediciones Temas de Hoy.

El Pais (1996 ${ }^{11}$ ): Libro de estilo. Madrid: Ediciones El País.

El Periódico de Cataluña (2002): Libro de estilo. Barcelona: Ediciones Primera Plana.

DAvies, Mark: Corpus del Español [en línea], Corpus del español. http://www.corpusdelespanol.org [Fecha de consulta: septiembre-octubre 2007].

FERNÁNDEZ RAMiRez, Salvador (1986): Gramática española 4. El verbo y la oración. Madrid: Arco / Libros

Mir y Noguera, Juan (1908): Prontuario de hispanismo y barbarismo. Madrid: Sáenz Jubera Hermanos (edición facsimilar en Analecta Editorial).

Real Academia Española (2005): Diccionario panhispánico de dudas. Madrid: Santillana. [en línea]. http://buscon.rae.es/dpdI/. 
Real Academia Española: Banco de Datos (CORJe) [en línea], Corpus diacrónico del español. http://www.rae.es [Fecha de consulta: septiembre-octubre 2007].

Reai Academia Española: Banco de Datos (CREA) [en línea], Corpus de referencia del español actual. http://www rae.es [Fecha de consulta: septiembre-octubre 2007].

Real Academia Española (2001): Nuevo tesoro lexicográfico de la lengua española. Madrid: Espasa-Calpe [ovD-ROM].

\section{Secundaria. Estudios}

CANo Agullar, Rafael (1986): "El vocalismo radical de los verbos españoles: Problemas de interpretación", en: Archivum XXXVI, 421-459.

- (2004): "La morfología histórica del español en los últimos cien años", en: Lexis 28, 1/2, 71-104.

Comistón Permanente de la Asociación de Academias de la lengua española (1987):

Primera Rexnión de Academias de la Lengua Española sobre El lenguaje y los $\mathrm{Me}$ dios de Comunicación. Madrid: Real Academia Española.

CoSERIU, Eugenio (1990): "El español de América y la unidad del idioma", en; I Simposio de Filología Iberoamericana (Sevilla, 26 al 30 de marzo de 1990). Zaragoza: Pórtico Libros, 43-75.

EuvIRA, Javier (1989): "Verbos defectivos en español", en: Actas do XXIX Congreso Internacional de Lingüística e Filoloxia Románicas. Univetsidade de Santiago de Compostela, 1989, La Coruña: Fundación "Pedro Barrié de la Maza, Conde de Fenosa", 1993, vol V, $573-580$

- (1993): "La adaptación morfológica del verbo culto", en: Epos, Revista de Filología 9, 151-168. Consultado en versión electrónica en: http://62.204.194.45:8080/fedora/get/ bibliuned:Epos-CA54AE57-2FEE-5C0A-87BE-78BB835B2DC8/PDF, octubre de 2007. - (1998): El cambio analógico. Madrid: Gredos.

García de la Concha, Víctor (2005): "Fernando Lázaro Carreter y la renovación de la Real Academia Española", en: Santos Río, Luis et al. (eds.): Palabras, norma, discurso. En menoria de Fernando Lázaro Carreter. Salamanca: Universidad de Salamanca, 23-32.

Koch, Peter (1988): "Norm und Sprache", en: Albrecht, Jörn/Lädtke, Jens/Thun, Harald (eds.): Energeia und Ergon. Sprachliche Variation, Sprachgeschichte, Sprachtypologie. Studia in honorem Eugenio Coseriu. Tübingen: Narr, II, 327-354.

Laín Entralgo, Pedro (1987): "Sesión inaugural", en: Comisión Pemanente de la Asociación de Academias de la Lengua Española, 13-17.

LARA, Luis Fernando (1979): El concepto de norma en lingüistica. México: El Colegio de México.

Lapesa Melgar, Rafael (1987): "Sesión inaugural", en: Comisión Permanente de la Asociación de Academias de la Lengua Española, 19-25.

-(1990): "El idioma del periodismo, ¿lengua especial?", en: García Domínguez, Pedro/ Gómez Font, Alberto (comps.): El idioma español en las agencias de prensa. Madrid: Fundación Germán Sánchez Ruipérez/Agencia EFE, 25-44.

MAL_KJeL, Yakov (1941): "A lexicographic mirage", en: Modern Language Notes 56, 34-42. 
Martinez Albertos, José Luis (1990): "El uso de la lengua en la comunicación periodística: aspectos culturales, políticos y sociales", en: Lingïística Española Actual 12/2, 175-196.

- (2003): "Lenguaje periodístico y corrección académica: La responsabilidad de los profesionales de la comunicación", en: González Calvo, José Manuel/Terrón González, Jesús/Galán Rodríguez, Carmen (eds.): Actas de las VI Jornadas de Metodologia y Didáctica de la Lengua Española: la Lengua en los Medios de Comunicación. Cáceres, 19-22 de noviembre de 2002. Cáceres: Universidad de Extremadura/Departamento de Filología Española/Instituto de Ciencias de la Educación, 45-68.

MÉndez García de Paredes, Elena (1999): "La norma idiomática del español: visión histórica", en: Philologia Hispalensis 13, 109-132.

OESTERREICHER, Wulf (2006): "La historicidad del lenguaje. Variación, diversidad y cambio lingüístico", en: Bustos Tovar, José Jesús de/Girón Alconchel, José Luis (eds.): Actas del VI Congreso Internacional de Historia de la Lengua Española. Madrid 29 de septiembre-3 de octubre de 2003. Madrid: Arco Libros, vol. 1, 137-158.

Pascual. Ronríguez, José Antonio/Prieto de los Mozos, Emilio (1998): “Sobre el estándar y la norma", en: Kent, Conrad/De la Calle, M. " Dolores (eds.): Visiones salmantinas (1898/1998). Salamanca: Universidad de Salamanca/Ohio Wesleylan Universiy, 63-95.

Pons Rouríguez, Lola/López SerenA, Araceli (2007): "Un episodio de la morfología histórica del español: la pérdida de la defectividad verbal en los medios, las gramáticas y el uso", en: BRAE, tomo 87, cuaderno 295 (enero-junio 2007), 59-95.

Rico, Francisco (1996): "De Nebrija a la Academia", en: Homenaje a Pedro Sainz Rodriguez, II. Estudios de Lengua y Literatura. Madrid: Fundación Universitaria Española, 519-525.

SECo, Manuel (1994): Las palabras del periodista. La Coruña: La Voz de Galicia. 